\title{
Parâmetros da habilidade competitiva no estabelecimento de populações caracterizam o potencial de produção individual em trigo e aveia
}

\author{
HENRIQUE P. SANTOS ${ }^{1,3}$ e CLAUDIO M. MUNDSTOCK ${ }^{2}$
}

(recebido: 4 de abril de 2001; aceito: 14 de novembro de 2001)

\begin{abstract}
Parameters of competitive ability in the establishment of populations characterise the individual yield potential in wheat and oat). Variation in production among plants is normally observed in monocultures and it can occur since the establishment of the populations by their competitive ability. This work was performed with the aim of selecting the parameters of competitive ability during the initial growth that are related to yield potential at the end of development. Plants of wheat (EMBRAPA 16) and oat (UFRGS 15) were grown on masons and field conditions and correlation among morphological parameters during the tillering and bloom stages were followed. During tillering, our results revealed that the pseudoculm diameter and leaf development were relevant to define the competitive ability by high correlation with dry mass, independently of species and environment. In these populations, the sequence of emergency of plants was inversely related to the apical development (to inflorescence) and to parameters that defined the competitive ability. This initial competitive ability was directly related to the size and yield potential (spikelets per inflorescence) of plants at the bloom stage. Our results indicate that the individual yield potential can be predicted by measurement of non destructive parameters of the competitive ability in the early stages of plant development.
\end{abstract}

RESUMO - (Parâmetros da habilidade competitiva no estabelecimento de populações caracterizam o potencial de produção individual em trigo e aveia). Em monoculturas, normalmente se observa uma variação de produção entre plantas, que pode estar ocorrendo desde o estabelecimento da população, pela habilidade competitiva destas. Este trabalho foi desenvolvido com o objetivo de selecionar parâmetros de habilidade competitiva, durante o estabelecimento, que se relacionam com o potencial de produção, no final do desenvolvimento. Plantas de trigo (EMBRAPA 16) e aveia (UFRGS 15) foram cultivadas em canteiros e a campo, correlacionando-se parâmetros morfológicos, nos estádios de afilhamento e florescimento. No afilhamento, nossos resultados revelaram que o diâmetro do pseudocolmo e o desenvolvimento foliar foram os parâmetros mais relevantes na caracterização da habilidade competitiva, pela alta associação com a massa seca, independente da espécie e do ambiente. Nestas populações, a ordem com que as plantas emergiram foi inversamente relacionada com o estádio de desenvolvimento apical (para inflorescência) e com os parâmetros que definiram a habilidade competitiva. Esta habilidade de competição inicial foi diretamente relacionada com o tamanho e a potencialidade de produção (espiguetas por inflorescência) das plantas, no estádio de florescimento. Os resultados indicam que o potencial de produção individual pode ser estimado por medidas de parâmetros não destrutivos, da capacidade de competição, nos primeiros estádios de desenvolvimento das plantas.

Key words - Triticum aestivum, Avena sativa, competitive ability, yield potential

\section{Introdução}

Quando se estabelece um cultivo, em monoculturas, espera-se que não ocorram grandes diferenças entre plantas, para se atingir maiores índices de rendimento. Entretanto, a complexidade do desenvolvimento em populações pode proporcionar variabilidades de produção entre plantas e reduzir os índices de produção por área. Estas flutuações de produção têm sido relacionadas com a capacidade de cada planta em competir, que é dependente da interação de fatores relacionados à

1. EMBRAPA Uva e Vinho, Rua Livramento, 515, Caixa Postal 130, 95700-000 Bento Gonçalves, RS.

2. Universidade Federal do Rio Grande do Sul, Faculdade de Agronomia, Departamento de Plantas de Lavoura, Av. Bento Gonçalves, 7712, Caixa Postal 776, 91501-970 Porto Alegre, RS.

3. Autor para correspondência: henrique@cnpuv.embrapa.br espécie, solo, clima e manejo de cultivo (Ledent 1982).

A competição entre plantas tem início desde o estabelecimento da população, sendo maximizada por maiores densidades de semeaduras (Galli 1996). Se todas as plantas iniciam o crescimento com a mesma massa, no mesmo dia, presume-se que a disponibilidade de recursos e a taxa de crescimento individual variam de acordo com a área disponível para cada planta, na população (Benjamin \& Hardwick 1986). Por isso, uma parcela de variabilidade de produção entre plantas pode ser explicada pela flutuação de densidade ou assimetria de espaçamento entre plantas, que ocorre na mesma população (Bonan 1991). Neste contexto, pequenos estresses ou diferenças na habilidade competitiva das plantas, em população, podem ser decisivos na determinação individual de produção, uma vez que as plantas perdem a capacidade de compensação para o rendimento. 
Considerando todos os fatores relacionados à espécie e ao ambiente que podem contribuir para a variação inicial de plantas em população, deve-se determinar os parâmetros que melhor caracterizam o estabelecimento. Isto porque, durante este período, estão sendo definidos a capacidade de competição e, possivelmente, o potencial de produção de cada planta. Segundo Benjamin (1990), quando o estabelecimento está completo, a variabilidade de massa seca é a melhor caracterização da variabilidade inicial entre plantas e, provavelmente, a melhor estimativa das diferenças no desenvolvimento futuro. Sendo assim, diferenças de massa e produção observadas entre plantas adultas podem ser explicadas por correspondentes diferenças de massa inicial, provavelmente, pela relação existente entre o tamanho inicial da planta e a habilidade de competir com plantas vizinhas. Krenzer et al. (1991) também sugerem que a qualidade de germinação ou de ambientes de cultivo pode ser determinada pelo estádio de desenvolvimento foliar do colmo principal e afilhos.

Além da escolha dos parâmetros que caracterizam plantas mais competitivas durante o estabelecimento, é importante relacioná-los com o desenvolvimento da inflorescência. A definição do número de espiguetas por espiga e flores por espigueta em plantas de trigo e aveia tem início durante o fase de afilhamento, que ocorre em geral no estádio de 4 a 6 folhas do colmo principal (Lozano et al. 1984, Peterman et al. 1985, Laitano 1997). Para as inflorescências destas espécies, que apresentam crescimento determinado, as condições de cultivo no período de iniciação do ápice tornam-se decisivas no estabelecimento do número potencial de espiguetas e flores férteis por inflorescência (Oosterhuis \& Cartwright 1983).

Apesar da grande importância que a fase de iniciação do ápice representa na produção por planta, poucos trabalhos relacionam as características de crescimento e desenvolvimento que as plantas apresentam neste período, com o potencial de produção no final do ciclo. Assim, este trabalho foi desenvolvido com os objetivos de caracterizar as plantas de trigo e aveia, em diferentes ambientes, durante o afilhamento e o florescimento, e de selecionar os parâmetros que melhor definem a capacidade de competição inicial e o potencial de produção, bem como a relação que existe entre os parâmetros analisados em ambas as etapas de desenvolvimento.

\section{Material e métodos}

Este trabalho foi realizado a partir de um conjunto de 3 experimentos, utilizando-se o cultivar de aveia UFRGS 15 e o cultivar de trigo EMBRAPA 16, sendo as sementes oriundas da safra de 1995, na Estação Experimental Agronomica da Universidade Federal do Rio Grande do Sul (EEA/UFRGS). A utilização destas duas espécies baseou-se nas diferenças em plasticidade de desenvolvimento (Galli 1996), idade de melhoramento (trigo mais antigo do que aveia) e desenvolvimento da inflorescência (Laitano, 1997), os quais podem proporcionar associações distintas entre parâmetros morfológicos e potencial de produção.

Nos dois primeiros experimentos (experimento I e II) objetivou-se a seleção de parâmetros relacionados com a capacidade de competição, no período de afilhamento, e os parâmetros relacionados com o potencial de produção, no florescimento. Deste modo, não foram avaliadas as mesmas plantas nas duas épocas de coleta. Com o intuito de confirmar as associações obtidas nestes experimentos, e correlacionar os parâmetros, entre as épocas de coleta, implantou-se o experimento III, no qual as plantas foram analisadas diretamente na população (sem destruição), utilizando-se os parâmetros não destrutivos associados com a massa seca.

Experimento I - cultivo a campo - O experimento foi conduzido na Estação Experimental de Agronomia (EEA/ UFRGS) em 1996, no município de Eldorado do Sul (RS, $30^{\circ} 50^{\prime} 52^{\prime \prime} \mathrm{S}$ e $51^{\circ} 38^{\prime} 08^{\prime \prime} \mathrm{W}$, com altitude média de $46 \mathrm{~m}$ ). O solo do local, cuja análise apresentou $\mathrm{pH}=5,0$; fósforo $=$ $10 \mu \mathrm{g} \cdot \mathrm{g}^{-1}$; potássio $=175 \mu \mathrm{g} \cdot \mathrm{g}^{-1}$ e matéria orgânica $=$ 2,3 g. $\mathrm{kg}^{-1}$, é classificado como Podzólico Vermelho-Escuro Distrófico (Paleudult), de textura franco-argilosa.

A semeadura foi realizada de forma mecanizada (junho de 1996), na densidade de 350 sementes por $\mathrm{m}^{2}$, em áreas de aproximadamente $500 \mathrm{~m}^{2}$, por espécie. Após a emergência das plântulas, na área de cada espécie, foram delimitadas aleatoriamente duas sub-áreas $\left(3,4 \mathrm{~m}^{2}\right.$, cada), que constituíram às áreas experimentais da primeira e da segunda coleta (afilhamento e florescimento), sendo que a área útil (área de coleta) foi de $1,5 \mathrm{~m}^{2}$ na região mediana de cada sub-área.

Como adubação utilizou-se a formulação 5-20-20 (NPK, $\left.300 \mathrm{~kg} \mathrm{ha}^{-1}\right)$, na semeadura, e duas coberturas com uréia (40 kg.ha ${ }^{-1}$ cada) quando as plantas apresentaram de duas a três folhas e quando foram visualizadas a $6^{\mathrm{a}}$ e a $7^{\mathrm{a}}$ folhas. Conforme a necessidade, as pragas e plantas invasoras foram controladas com a aplicação de inseticidas e herbicidas específicos.

Experimentos II e III - cultivo em canteiros - Estes experimentos foram instalados em 1996 e 1997, respectivamente, na área experimental do Departamento de Plantas de Lavoura (Faculdade de Agronomia/UFRGS), em Porto Alegre (RS, $30^{\circ} 01^{\prime} 53^{\prime \prime} \mathrm{S}$ e $51^{\circ} 13^{\prime} 19^{\prime}$ W com $10 \mathrm{~m}$ de altitude). Em ambos experimentos, as espécies (trigo e aveia) foram cultivadas em dois canteiros formados por caixas de madeira $(2,7 \times 1,4 \times$ $0,3 \mathrm{~m}$ ), sobre piso cimentado. Cada caixa de madeira constituiu uma área total de $3,78 \mathrm{~m}^{2}$, por espécie, contendo oito linhas dispostas ao longo do maior comprimento da caixa e espaçadas a $0,17 \mathrm{~m}$. No experimento II, a área útil foi formada pelas quatro linhas centrais, descontando $0,40 \mathrm{~m}$ em cada extremidade, e dividida em duas partes iguais (quatro linhas de $0,8 \mathrm{~m}$ ), 
deixando-se $0,3 \mathrm{~m}$ como bordadura entre as partes. Cada parte constituiu uma época de amostragem (afilhamento ou florescimento). Esta marcação não foi realizada no experimento III, em função da primeira análise ter sido realizada diretamente na parcela, sem a coleta das plantas. Neste caso, foram selecionadas para análise apenas as duas linhas centrais do canteiro de cada espécie, descontando $0,40 \mathrm{~m}$ em cada extremidade, como bordadura.

Estas caixas foram preenchidas com uma mistura de solo mineral e cama de aviário, cuja análise química apresentou: $\mathrm{pH}=5,0$ e 4,5; fósforo $=27$ e $68 \mu \mathrm{g} \cdot \mathrm{g}^{-1}$; potássio $=190$ e 186 $\mu \mathrm{g} \cdot \mathrm{g}^{-1}$ e matéria orgânica $=2,1$ e $2,3 \mathrm{~g} \cdot \mathrm{kg}^{-1}$, respectivamente para os experimentos II e III, não sendo necessária a adubação de base. A adubação com uréia foi realizada em cinco aplicações (30 kg.ha- ${ }^{-1}$ cada) entre a emissão da $2^{\mathrm{a}}$ e $6^{\mathrm{a}}$ folhas.

As sementes, pré-selecionadas em peneiras de furos oblongos, com diâmetro transversal maior que 2,2 e 2,5 mm para trigo e aveia, respectivamente, foram distribuídas em papel filtro e colocadas em germinador (UR $100 \%, 20^{\circ} \mathrm{C}$ ). Quando se observou $4 \mathrm{~mm}$ de protusão da radícula, as sementes foram plantadas manualmente à $1,5 \mathrm{~cm}$ de profundidade e $1,5 \mathrm{~cm}$ de espaçamento na linha, correspondendo a 390 plantas. $\mathrm{m}^{-2}$. No experimento II, este plantio foi realizado na segunda quinzena de maio, e no experimento III na primeira quinzena de agosto. Em ambos experimentos, após o plantio fez-se um acompanhamento diário da emergência adotando-se como data de emergência o dia em que a contagem das plantas emergidas ultrapassou o valor de $50 \%$ das sementes plantadas. No experimento III, durante a emergência, as plantas situadas nas duas linhas centrais foram marcadas diariamente, para obtenção da seqüência de emergência.

Avaliações - Em todos os experimentos foram realizadas duas avaliações, uma no período de afilhamento e outra durante o florescimento. Na primeira avaliação, buscou-se coletar e avaliar as plantas durante a fase de transição entre os períodos préfloral e floral, ou iniciação da inflorescência. Para realizar a coleta nesta fase, três plantas da bordadura foram coletadas aleatoriamente e analisadas semanalmente, como experimento piloto, verificando-se o aparecimento do "duplo anel" ou primórdios de ramificação de $1^{\mathrm{a}}$ ordem, que caracterizam a fase de transição em trigo e aveia, respectivamente (Bonnett 1966).

Nesta avaliação inicial, em todos experimentos, foram analisados três parâmetros morfológicos não destrutivos (estádios de desenvolvimento foliar do colmo principal e de afilhos, comprimento da bainha e diâmetro do pseudocolmo) e, apenas nos experimentos I e II, os parâmetros destrutivos massa seca $\left(60^{\circ} \mathrm{C}, 72 \mathrm{~h}\right)$ e estádio de desenvolvimento do ápice.

$\mathrm{O}$ estádio de desenvolvimento foliar foi determinado conforme a escala proposta por Haun (1973), também denominada de "escala Haun", que se baseia no número de folhas expandidas (com lígula visível) mais um valor decimal relativo a penúltima folha, que é atribuído a última folha (não expandida). Esta escala para os afilhos teve duplo propósito, caracterizando tanto a presença como o desenvolvimento destes.
O comprimento da bainha, que caracteriza a estatura das plantas antes de ocorrer a extensão dos entrenós (colmo verdadeiro), foi estabelecido através da medida da bainha da última folha expandida (no colmo principal), desde a base da planta (faixa de transição de cores sub e sobre-solo) até a altura da última lígula visível, conforme o método descrito por Lozano et al. (1984). Ainda no colmo principal, obteve-se o diâmetro do pseudocolmo, tomando-se a medida transversal a $1 \mathrm{~cm}$ da base da planta (acima da superfície do solo).

O estádio de iniciação do ápice, no colmo principal, foi determinado observando-se a morfologia do ápice e comparando-a com a escala proposta por Bonnett (1966). Esta escala é descrita por letras maiúsculas variando de A a J, em aveia, e de A a I, em trigo. Em aveia a iniciação da inflorescência é representada pela letra $\mathrm{C}$, e em trigo pela letra $\mathrm{D}$.

A segunda avaliação foi realizada no estádio de florescimento, quando observou-se $50 \%$ das anteras nas espiguetas das inflorescências. Nesta análise, foram avaliadas as características da inflorescência do colmo principal (comprimento, número de nós no ráquis, número de ramificações e número de espiguetas férteis e estéreis) e as características da planta (estatura, massa seca e número de afilhos férteis ou estéreis). A estatura das plantas foi medida desde a transição raiz-parte aérea até o ápice do ráquis da inflorescência. O comprimento da inflorescência foi considerado a medida entre o primeiro nó, na base, até o ápice do ráquis. As espiguetas, foram consideradas férteis quando apresentavam antécios férteis (com anteras visíveis) ou potencialmente férteis (com anteras presentes mas ainda não expostas). Os afilhos foram considerados férteis quando apresentaram inflorescências. $\mathrm{O}$ número de nós no ráquis e ramificações foram avaliados somente nos experimentos I e II.

O tempo nos três experimentos foi caracterizado em dias após a emergência (DAE), data e soma térmica. A soma térmica foi determinada pelo acúmulo diário de temperatura em graus-dia (GD), conforme a metodologia empregada por Bauer et al. (1984).

Em todos os experimentos, o delineamento experimental foi completamente casualizado, sendo atribuído por sorteio a seleção das áreas experimentais e a seleção das áreas de cada época de avaliação, por espécie. Em cada época de avaliação, foram coletadas todas as plantas da área útil correspondente, separando-se aleatoriamente para análises 150 plantas, no experimentos I e II, e 120 plantas, no experimento III, o que correspondeu a aproximadamente $90 \%$ do número total de plantas coletadas. Deste modo, cada planta coletada e analisada foi considerada como uma unidade experimental (repetição), para se ter uma caracterização da variação individual de plantas da mesma espécie, crescidas em população, e para se ter suporte (em número de plantas) na obtenção de coeficientes de correlação simples (descritos abaixo), realizados entre os parâmetros morfológicos.

Os resultados obtidos foram inicialmente submetidos à análise da variância, sendo que os parâmetros significativamente distintos entre espécies e ambientes, pelo teste $\mathrm{F}(5 \%)$, foram submetidos a comparação das médias pelo teste de 
Tukey a 5\% de significância. Entre os parâmetros de cada coleta e entre coletas, também se realizou a análise de correlação simples, nas diferentes espécies e ambientes. Os coeficientes das correlações foram avaliados pelo teste $\mathrm{T}$ (baseado nos graus de liberdade de cada experimento) a $1 \%, 0,5 \%$ e 0,1\% de probabilidade (Gomes 1987).

\section{Resultados e Discussão}

Habilidade competitiva no desenvolvimento inicial - As plantas cultivadas no campo apresentaram menor massa seca, maior estatura (representado pelo comprimento da bainha foliar) e menor desenvolvimento de afilhos (tabela 1), o que caracteriza plantas sob grande competição (Galli 1996). Por outro lado, estas mesmas plantas, principalmente as de trigo, apresentaram semelhante desenvolvimento foliar do colmo principal, quando comparadas com aquelas cultivadas em canteiros, no mesmo ano (experimento II). Isto contradiz, em parte, Krenzer et al. (1991) que afirmaram que o desenvolvimento foliar do colmo principal e dos afilhos são características representativas das condições de cultivo das plantas. Entretanto, a soma da escala foliar, a qual engloba o desenvolvimento foliar do colmo principal e afilhos, proporcionou melhor caracterização das condições de cultivo nas diferentes espécies e ambientes (tabela 1). Desta forma, a competição entre plantas teve maior efeito sobre o desenvolvimento dos afilhos (elevado coeficiente de variação - C.V., escala Haun dos afilhos, tabela 1) do que sobre o colmo principal, principalmente no cultivar de trigo, o que salienta a supressão do desenvolvimento destes em detrimento ao colmo principal, quando as plantas são submetidas a condições de estresse, como profundidade de semeadura, disponibilidade hídrica ou espaço físico (Peterson et al. 1989, Krenzer et al. 1991).

Dentre os afilhos, observou-se que as espécies, independentemente do ambiente, apresentaram maior desenvolvimento foliar do primeiro (A1) e do segundo afilho (A2), sendo a maior freqüência para o segundo (menor C.V. em ambas espécies, tabela 1). Algumas plantas mais vigorosas também apresentaram os afilhos do coleóptilo (A0) e da terceira folha (A3), porém estiveram ausentes na maioria das plantas, em todos experimentos (tabela 1). Isto sugere que os cultivares (UFRGS 15 e EMBRAPA 16) empregados neste trabalho não apresentaram, como característica, o desenvolvimento do afilho do coleóptilo, que tem sido citado como um dos parâmetros na seleção de plantas mais vigorosas e produtivas (Peterson et al. 1989, Liang \& Richards 1994).

Para caracterizar as plantas competitivas no estabelecimento da população, correlacionou-se as

Tabela 1. Médias dos parâmetros analisados durante o afilhamento, em plantas de aveia (UFRGS 15) e trigo (EMBRAPA 16), cultivadas a campo (experimento I), EEA/UFRGS, Eldorado do Sul-RS (1996), e em canteiros (experimento II e III), FA/UFRGS, Porto Alegre-RS (1996 e 1997).

\begin{tabular}{|c|c|c|c|c|c|c|c|c|c|c|}
\hline \multirow[t]{2}{*}{ Experimentos } & \multirow{2}{*}{$\begin{array}{l}\text { Massa } \\
(\mathrm{g})\end{array}$} & \multirow{2}{*}{\multicolumn{2}{|c|}{$\begin{array}{l}\text { Estatura } \\
\text { Diâmetro do } \\
\begin{array}{ll}\text { (C. bainha) })^{1} & \text { pseudocolmo } \\
(\mathrm{cm}) & (\mathrm{mm})\end{array}\end{array}$}} & \multirow[b]{2}{*}{$\mathrm{CP}$} & \multicolumn{4}{|c|}{ Desenvolvimento foliar ${ }^{2}$} & \multirow[b]{2}{*}{ Soma } & \multirow{2}{*}{$\begin{array}{l}\text { Estádio de } \\
\text { iniciação } \\
\text { do ápice }^{3}\end{array}$} \\
\hline & & & & & A1 & A2 & A3 & $\mathrm{A} 0$ & & \\
\hline \multicolumn{11}{|c|}{ Aveia } \\
\hline I - campo & $0,19 \mathrm{~b}$ & $6,2 \mathrm{a}$ & $2,6 b$ & $5,6 \mathrm{a}$ & $1,4 \mathrm{~b}$ & $1,1 \mathrm{~b}$ & $0,1 \mathrm{a}$ & $0,2 \mathrm{a}$ & $8,4 \mathrm{~b}$ & $\mathrm{Ga}$ \\
\hline II - canteiro & $0,24 \mathrm{a}$ & $4,2 \mathrm{~b}$ & $2,5 \mathrm{~b}$ & $5,4 \mathrm{~b}$ & $2,5 \mathrm{a}$ & $1,6 \mathrm{a}$ & $0,0 \mathrm{a}$ & $0,0 \mathrm{a}$ & $9,5 \mathrm{a}$ & $\mathrm{Cb}$ \\
\hline III - canteiro & - & $4,8 \mathrm{~b}$ & $2,9 \mathrm{a}$ & $5,2 \mathrm{c}$ & $2,1 \mathrm{a}$ & $1,6 \mathrm{a}$ & $0,0 \mathrm{a}$ & $0,2 \mathrm{a}$ & $9,1 \mathrm{a}$ & - \\
\hline C.V. $(\%)$ & 41 & 11 & 15 & 7 & 90 & 62 & 232 & 349 & 26 & 13 \\
\hline \multicolumn{11}{|c|}{ Trigo } \\
\hline I - campo & $0,18 \mathrm{~b}$ & $11,8 \mathrm{a}$ & $2,1 \mathrm{a}$ & $5,4 \mathrm{~b}$ & $0,1 \mathrm{c}$ & $0,2 \mathrm{c}$ & $0,1 \mathrm{~b}$ & $0,0 \mathrm{~b}$ & $5,7 \mathrm{c}$ & $\mathrm{E} \mathrm{a}$ \\
\hline II - canteiro & $0,22 \mathrm{a}$ & $5,5 \mathrm{c}$ & $2,3 \mathrm{a}$ & $5,3 \mathrm{~b}$ & $2,0 \mathrm{a}$ & $1,8 \mathrm{~b}$ & $0,2 \mathrm{~b}$ & $0,1 \mathrm{~b}$ & $9,8 \mathrm{~b}$ & $\mathrm{D} b$ \\
\hline III - canteiro & - & $6,2 \mathrm{~b}$ & $2,2 \mathrm{a}$ & $6,0 \mathrm{a}$ & $1,3 \mathrm{~b}$ & $2,2 \mathrm{a}$ & $1,8 \mathrm{a}$ & $1,4 \mathrm{a}$ & $12,9 \mathrm{a}$ & - \\
\hline C.V. $(\%)$ & 42 & 23 & 17 & 6 & 135 & 94 & 190 & 523 & 18 & 21 \\
\hline \multicolumn{11}{|c|}{ Comprimento da bainha da última folha expandida. } \\
\hline \multicolumn{11}{|c|}{$\begin{array}{l}3 \text { Estádio de iniciação do ápice, no colmo principal, conforme descrito por Laitano (1997), adaptado de Bonnett (1966). } \\
\text { Médias seguidas da mesma letra na coluna, não se diferenciam pelo teste de Tukey a 5\% de probabilidade. } \\
\text { Experimento I e II = } 150 \text { plantas, Experimento III = } 120 \text { plantas avaliadas. }\end{array}$} \\
\hline
\end{tabular}


características avaliadas nesta etapa com a massa seca que, de acordo com alguns trabalhos, é provavelmente a melhor estimativa de suas futuras performances de produção (Lafond \& Baker 1986, Benjamin 1990, Gan \& Stobbe 1996). Na análise das diferentes populações (ambientes e espécies), obtidas nos dois primeiros experimentos, a massa seca esteve diretamente relacionada com o desenvolvimento foliar (escala Haun do colmo principal e do primeiro e segundo afilhos) e com o diâmetro do pseudocolmo (tabela 2), que é formado, basicamente, pelas dimensões foliares. $\mathrm{O}$ crescimento foliar também se expressa sobre o comprimento da bainha o qual, durante o afilhamento, proporciona a estatura das plântulas. Entretanto, a associação desta medida com a massa seca mostrou-se distinta entre as espécies estudadas. Para aveia esta associação apresentou valores baixos (próximos ao limite mínimo de significância), independente do ambiente de cultivo (tabela 2), demonstrando que na população desta espécie também ocorreram plantas de baixa estatura e com alto diâmetro do pseudocolmo, massa seca e desenvolvimento foliar. Já o cultivar de trigo, tanto no campo como no canteiro, apresentou altos valores de correlação $(r>0,60)$, para esta associação. Com isto, as plantas de trigo com maior estatura foram as maiores plantas (maior massa seca) e, consequentemente, com maior desenvolvimento foliar. Comparando a evolução de ambas espécies (trigo e aveia), pode-se inferir que a maior associação da estatura com a massa seca talvez seja uma característica desejável, uma vez que o trigo apresenta um programa de melhoramento mais antigo do que a aveia.

A proporcionalidade ou associação que ocorre entre características de crescimento e desenvolvimento de uma planta pode revelar a adaptabilidade às condições a que está submetida durante o seu desenvolvimento (Lozano et al. 1984). Isto se comprovou nas fortes associações da massa seca com o desenvolvimento do ápice no cultivar de trigo, tanto nos cultivos a campo como em canteiros (tabela 2). Contudo, em aveia, esta associação foi alta apenas no cultivo em canteiros (experimento II). Isto demonstra que as plantas de trigo apresentaram maior sincronismo entre o crescimento das estruturas foliares e o desenvolvimento do ápice do que as plantas de aveia, nos diferentes ambientes.

$\mathrm{O}$ sincronismo entre o desenvolvimento e o crescimento das diferentes estruturas na planta não pode ser encarado como um parâmetro totalmente estável geneticamente. Isto porque as plantas de trigo e aveia apresentaram um padrão de ontogenia do ápice altamente dependente das condições de cultivo, comparado com os parâmetros de crescimento foliar do colmo principal (experimentos I e II, tabela 1). Nos canteiros, o estádio de desenvolvimento foliar foi 5,4 e 5,3 com soma térmica de 615 e $545{ }^{\circ} \mathrm{C}$, e a campo o estádio do desenvolvimento foi de 5,6 e 5,4 e a soma térmica de 640 e $544{ }^{\circ} \mathrm{C}$, respectivamente para aveia e trigo. Embora houvesse semelhança de desenvolvimento foliar e soma térmica nos dois ambientes, as plantas nos canteiros apresentaram menor desenvolvimento do ápice (estádios C e D) do que no campo (estádios G e E). Isto indica que, no campo, o ápice foi privilegiado em relação às demais partes da planta pela dominância apical. Assim, as plantas sob maiores estresses (como no campo) podem ter antecipado o desenvolvimento do ápice para um mesmo crescimento das estruturas foliares, pela redução dos estádios iniciais de desenvolvimento da inflorescência (Frank \& Bauer

Tabela 2. Coeficientes de correlação entre o crescimento em massa seca e os parâmetros avaliados no afilhamento, de 150 plantas de aveia (UFRGS 15) e de trigo (EMBRAPA 16), cultivados a campo (experimento I) e em canteiros (experimento II), no ano de 1996. Coeficientes de correlação significativos aos níveis de $0,5 \%(\mathrm{r}>0,22)$ e $0,1 \%(\mathrm{r}>0,26)$ de probabilidade.

\begin{tabular}{lcccc}
\hline & \multicolumn{2}{c}{ Experimento I } & \multicolumn{2}{c}{ Experimento II } \\
Parâmetros & Aveia & Trigo & Aveia & Trigo \\
\hline Escala Haun do colmo principal & 0,70 & 0,71 & 0,56 & 0,52 \\
Escala Haun do afilho do coleóptilo & - & - & - & 0,25 \\
Escala Haun do afilho da 1 a folha & 0,74 & 0,24 & 0,74 & 0,84 \\
Escala Haun do afilho da 2 $2^{a}$ folha & 0,69 & 0,54 & 0,69 & 0,69 \\
Escala Haun do afilho da 3a folha & 0,30 & 0,54 & - & 0,37 \\
Diâmetro do pseudocolmo & 0,82 & 0,90 & 0,77 & 0,81 \\
Comprimento da bainha & 0,29 & 0,85 & 0,38 & 0,66 \\
Desenvolvimento do ápice & 0,38 & 0,86 & 0,62 & 0,84 \\
\hline
\end{tabular}


1996). As diferenças entre os ambientes podem também estar relacionadas às condições iniciais favoráveis, proporcionadas nos canteiros, que tendem a retardar o desenvolvimento do ápice e estimular o acúmulo de massa seca antes da iniciação da inflorescência (Laitano 1997).

No cultivo em canteiros em 1997 (experimento III), no qual as plantas foram analisadas intactas, encontrouse as mesmas associações de crescimento e desenvolvimento foliar, obtidas nos cultivos anteriores (figura 1A, B). Entretanto, este experimento possibilitou a confirmação de que as diferenças iniciais detectadas e analisadas acima (diâmetro do pseudocolmo, desenvolvimento foliar do colmo principal e afilhos) foram significativamente e negativamente relacionadas com ordem de emergência das plantas na população. Isto está de acordo com alguns trabalhos que salientam que a variação inicial, caracterizada por diferentes graus de dominância entre plantas, depende principalmente do tempo que as plantas levam para emergir na população (Knight 1983, Benjamin 1990, Gan \& Stobbe 1996). De maneira geral, as plantas que emergiram mais tarde no dossel foram as que apresentaram menor desenvolvimento e crescimento, caracterizado pelas associações negativas entre o crescimento e desenvolvimento foliar do colmo principal e afilhos (figura 1A, B). Além disto, em função da alta associação entre diâmetro do pseudocolmo e massa seca estabelecida anteriormente (tabela 2), pode-se inferir que são plantas menores e com desenvolvimento menor do ápice. $\mathrm{O}$ efeito da emergência foi evidente em ambas espécies, sendo que o cultivar de aveia apresentou maior amplitude de emergência (6 dias) do que o cultivar de trigo (3 dias), o que justifica os maiores coeficientes de correlação entre o desenvolvimento foliar e a ordem de emergência nesta espécie (figura 1A).

Potencial de produção no florescimento - As populações das duas espécies apresentaram, ou mantiveram durante o ciclo, plantas com distintas características de crescimento e potencial de produção. Dentro das características de planta, o cultivar de trigo a campo apresentou maior redução de crescimento no florescimento, comparado com a massa seca medida nos canteiros (tabela 3). Além disso, estas mesmas plantas apresentaram maior estatura. Conforme Bonan (1991), as flutuações em tamanho de plantas caracterizam as condições em que se desenvolveram, sendo as maiores estaturas relacionadas com maiores densidades de semeaduras, que proporciona maior competição entre indivíduos. Assim, no cultivo a campo as plantas de trigo foram submetidas a maiores níveis de competição do que nos canteiros. Esta competição também foi caracterizada durante o período de afilhamento (discutido anteriormente), justificando que na população estabelecida, as diferenças entre plantas são mantidas durante todo o ciclo (Knight 1983, Benjamin

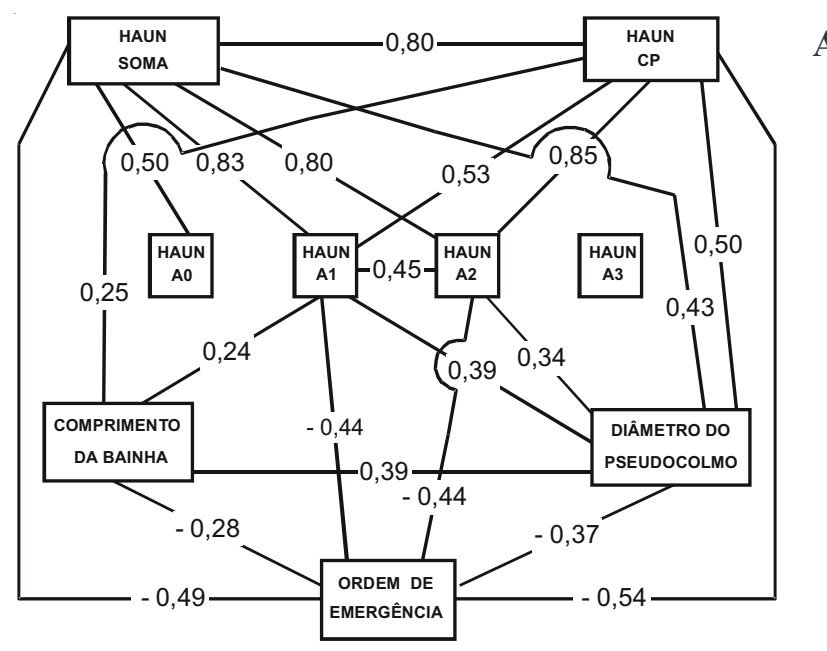

A

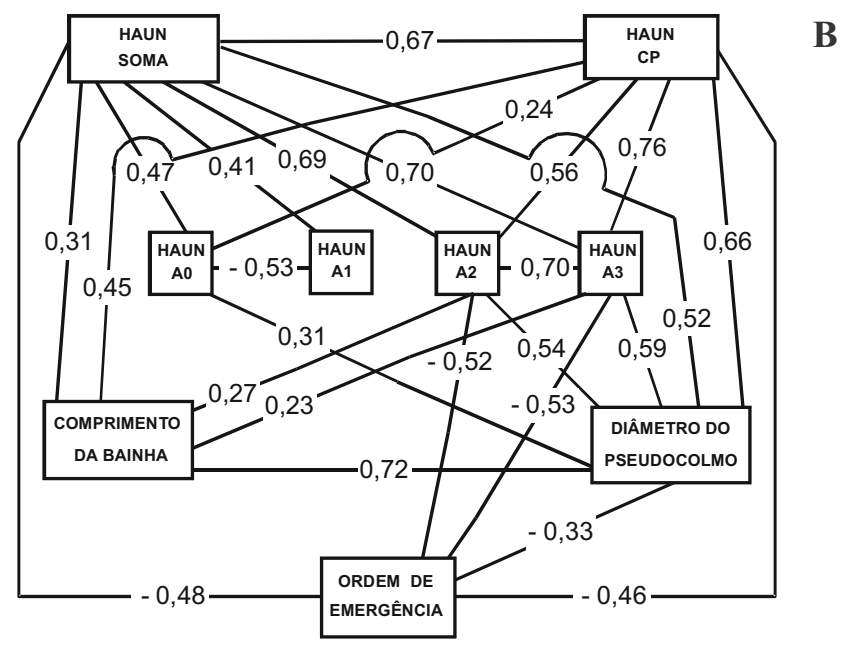

Figura 1. Diagrama de correlações entre a ordem de emergência das plantas, diâmetro do pseudocolmo, comprimento da bainha foliar (estatura) e a escala de desenvolvimento foliar, determinada conforme Haun (1973), no colmo principal (Haun CP) e nos afilhos do coleóptilo (Haun A0), da primeira folha (Haun A1), da segunda folha (Haun A2) e da terceira folha (Haun A3), que em conjunto formam o somatório foliar por planta (Haun soma). Estes parâmetros foram avaliados na fase de afilhamento, em plantas de (A) aveia (UFRGS 15) e (B) trigo (EMBRAPA 16), cultivados em canteiros (experimento III). FA/UFRGS, Porto Alegre-RS, 1997. Dentro de cada variedade foram avaliadas 120 plantas, apresentando-se significativos os coeficientes de correlação maiores que $0,23(1 \%), 0,25(0,5 \%)$ e $0,29(0,1 \%$ de probabilidade). Os parâmetros que não apresentam conexão entre si têm probabilidade $>1 \%$. 
1990). Entretanto, este comportamento não ocorreu da mesma forma para aveia. Durante o estabelecimento, as plantas de aveia, a campo, apresentaram um crescimento menor do que nos canteiros (tabela 1). Porém, no florescimento, as plantas de aveia, no campo, foram superiores, em crescimento, às plantas de aveia dos canteiros (tabela 3). Este tipo de contradição pode acontecer, devido ao fato de que no cultivo a campo não há homogeneidade de distribuição de plantas, fertilidade ou umidade do solo, que podem favorecer ou suprimir o crescimento individual (Benjamin \& Hardwick 1986, Bonan 1991). Assim, para se ter uma comparação válida entre os ambientes (campo e canteiros) seria necessário uma maior área de amostragem no cultivo a campo. Nos canteiros, o controle da variabilidade de crescimento foi eficaz, já que houveram pequenas diferenças em massa seca, nos dois anos de cultivo, principalmente para aveia (experimento II e III, tabela 3).

Apesar da semelhança de crescimento (massa seca) entre os cultivos nos canteiros, significativas diferenças foram observadas no número de afilhos por planta. No último ano (experimento III), as plantas de trigo e aveia apresentaram maior número de afilhos, destacando-se o número de afilhos estéreis (sem inflorescências) (tabela 3). Na comparação entre os dois anos de cultivo, a principal diferença foi a data de plantio, sendo que no último ano (experimento III) esta foi realizada quase três meses após a data do primeiro (experimento II). Esta diferença fez com que as plantas do experimento III se desenvolvessem sob maiores fotoperíodos e temperaturas, o que promovem maior taxa de crescimento e redução das etapas de desenvolvimento (Kirby 1995, Miralles et al. 2001). Deste modo, estas plantas foram estimuladas ao desenvolvimento de afilhos de maior ordem, que em geral não apresentam capacidade de produção no final do ciclo ou senescem durante o alongamento (Wobeto 1994). Além disso, neste terceiro experimento as plantas de trigo e aveia apresentaram maior número de espiguetas por inflorescência ou maior potencial de produção (no colmo principal, tabela 3), o que, como citado para os afilhos, também pode estar relacionado ao incremento na taxa de iniciação de primórdios, por temperaturas mais elevadas durante a fase de iniciação das inflorescências (Kirby 1995). Contudo, ainda que o número de afilhos tenha caracterizado plantas mais produtivas, não há como descartar a possibilidade de que, se estas plantas não apresentassem estes afilhos, apresentariam maiores inflorescências. De acordo com o trabalho de Chafai-Elalaoui \& Simmons (1988), plantas de cevada, em população, cresceram e produziram mais quando todos os afilhos foram removidos, salientando que estes

Tabela 3. Médias dos parâmetros analisados durante o florescimento, em plantas de aveia (UFRGS 15) e trigo (EMBRAPA 16), cultivadas a campo (experimento I), EEA/UFRGS, Eldorado do Sul-RS (1996), e em canteiros (experimento II e III), FA/UFRGS, Porto Alegre-RS (1996 e 1997).

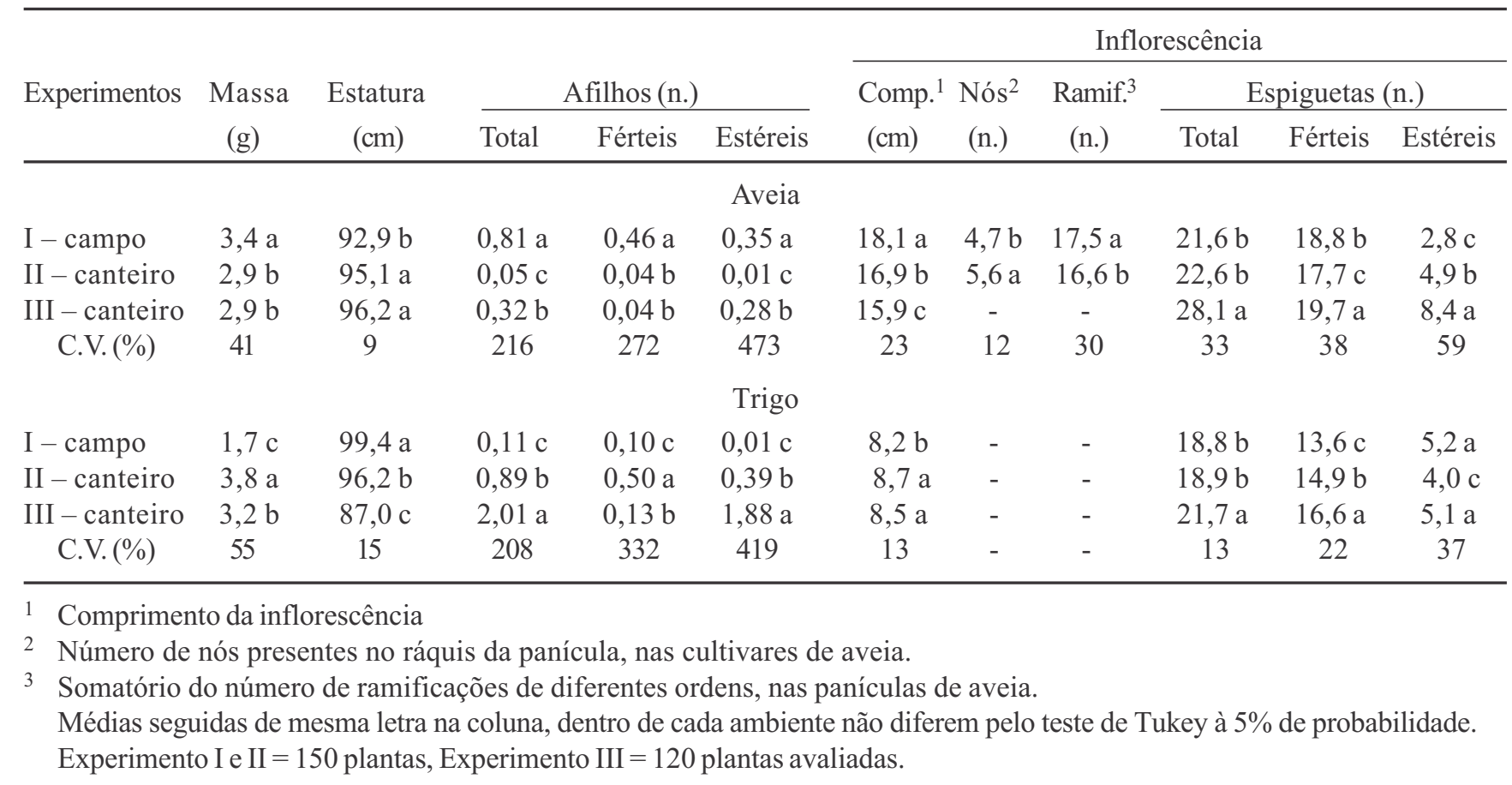


competiram com o colmo principal por fotoassimilados. Além disto, Shanahan et al. (1985) salientaram que o número máximo de colmos obtidos no final do afilhamento, não está relacionado com a produção por planta, em população, mas sim o número de colmos que sobrevivem até o final do florescimento.

O potencial de produção, caracterizado pelo número de espiguetas presentes por inflorescência, quando correlacionado com as características de crescimento das plantas, proporcionou positivos e significativos coeficientes com massa seca e estatura, nos diferentes ambientes (tabela 4, figura 2). Assim, por alometria, as plantas maiores foram as que apresentaram as maiores inflorescências, o que justifica uma relação alométrica entre o potencial de produção e o crescimento das diferentes partes da planta (Ledent 1982).

Os fatores que interferem na formação dos primórdios no ápice, durante a iniciação da inflorescência, tendem a influenciar diretamente no número de espiguetas férteis no final ciclo (Peterman et al. 1985). Isto pode ser comprovado pela associação significativa entre o número de espiguetas total e férteis por inflorescência (tabela 4, figura 2). Qualquer fator que, durante a fase de iniciação dos primórdios da inflorescência, promove a redução do número de espiguetas irá afetar diretamente o número de espiguetas férteis, no florescimento. O número de espiguetas estéreis não demonstrou esta mesma relação, sendo variável tanto entre ambientes como entre espécies (tabela 4, figura 2), e em alguns casos apresentando associação negativa com o número total de espiguetas (tabela 4), ou seja, as

Tabela 4. Coeficientes de correlação entre o potencial de produção por planta, caracterizado pelo número total de espiguetas por inflorescência no colmo principal, e os parâmetros avaliados no florescimento, em 150 plantas de aveia (UFRGS 15) e de trigo (EMBRAPA 16), cultivados a campo (experimento I) e em canteiros (experimento II), no ano de 1996. Coeficientes de correlação significativos aos níveis de $0,5 \%(r>0,22)$ e $0,1 \%(r>0,26)$ de probabilidade.

\begin{tabular}{lcccc}
\hline & \multicolumn{2}{c}{ Experimento I } & \multicolumn{2}{c}{ Experimento II } \\
Parâmetros & Aveia & Trigo & Aveia & Trigo \\
\hline Estatura & 0,51 & 0,51 & 0,67 & 0,72 \\
Massa seca & 0,61 & 0,71 & 0,86 & 0,61 \\
Comprimento da inflorescência & 0,66 & 0,90 & 0,79 & 0,89 \\
N. de nós da panícula & 0,73 & - & 0,64 & - \\
N. de ramificações da panícula & 0,83 & - & 0,92 & - \\
N. de espiguetas férteis & 0,86 & 0,87 & 0,93 & 0,94 \\
N. de espiguetas estéreis & $\mathrm{ns}$ & $-0,45$ & $\mathrm{~ns}$ & $-0,50$ \\
N. total de afilhos & 0,36 & 0,31 & $\mathrm{~ns}$ & 0,52 \\
N. de afilhos férteis & 0,37 & 0,30 & $\mathrm{~ns}$ & 0,56 \\
\hline
\end{tabular}

menores inflorescências foram as que apresentaram maior número de espiguetas estéreis. No geral, o número de espiguetas estéreis apresentou dependência tanto do ambiente como das condições fisiológicas das plantas, durante o desenvolvimento.

Em condições favoráveis, as plantas de aveia apresentam maior capacidade em incrementar o número de espiguetas por inflorescência, do que em trigo. Isto porque, em aveia, as inflorescências podem desenvolver ramificações de maior ordem, na base da panícula, no final da fase de iniciação (Bonnett 1966). Esta interdependência entre ramificações e o número de espiguetas, em aveia, proporcionou altos valores de correlação $(r>0,80)$ entre esses parâmetros, tanto nos canteiros como no campo, em 1996 (tabela 4). O número de ramificações da panícula também esteve associado com o número de nós no ráquis, independente do
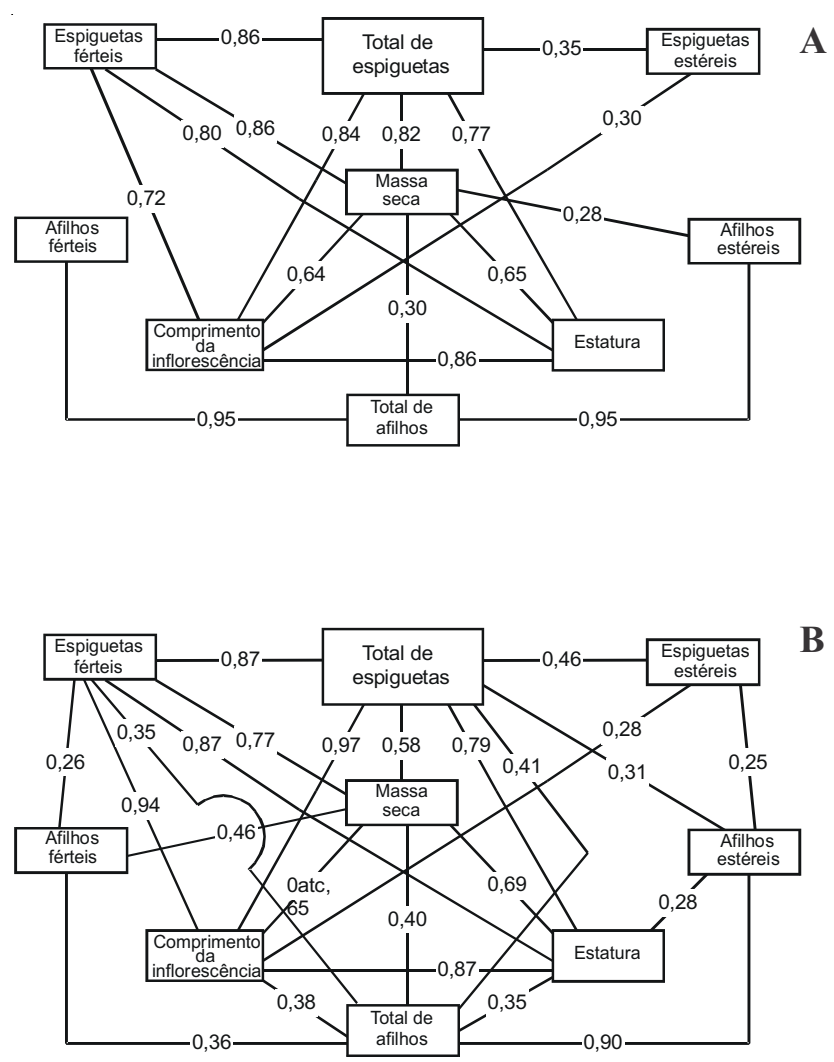

Figura 2. Diagrama de correlações entre os parâmetros avaliadas no florescimento, em plantas de aveia (UFRGS 15) (A) e de trigo (EMBRAPA 16) (B), cultivadas em canteiros (experimento III). FA/UFRGS, Porto Alegre-RS, 1997. Dentro de cada variedade foram avaliadas 120 plantas, apresentando-se significativos os coeficientes de correlação maiores que $0,23(1 \%), 0,25(0,5 \%)$ e $0,29(0,1 \%$ de probabilidade). Os parâmetros que não apresentam conexão entre si têm probabilidade $>1 \%$. 
ambiente (dados não mostrados), sugerindo que, numa panícula de aveia só é possível aumentar o número de grãos através do número de primórdios de ramificações, tanto de ordem primária (no ráquis) como em maiores ordens (ramificações de ramificações). Entretanto, as espiguetas das últimas ramificações (maiores ordens) são na maioria estéreis, como se pode observar no cultivar de aveia nos canteiros (experimento II e III), que apresentaram maior número de espiguetas estéreis do que os trigos (tabela 3 ).

Associação entre a habilidade competitiva e o potencial de produção - O potencial de produção de uma planta de aveia ou trigo se expressa no número de espiguetas presentes por inflorescência e o número de grãos por espigueta que esta pode apresentar no final do ciclo. As observações das características de crescimento e desenvolvimento durante o estabelecimento da população (fase de afilhamento) e no florescimento, sobre a mesma planta (experimento III), mostram que o potencial de produção vem sendo definido muito cedo na vida da planta.

No geral, as plantas com maior vigor inicial, caracterizadas por maior diâmetro do pseudocolmo, apresentaram maior massa seca e estatura no final do ciclo em ambas espécies (tabelas 5,6). Estas plantas também apresentaram um maior número de espiguetas total e férteis por inflorescência, representado pela alta associação entre os parâmetros de ambas etapas de avaliações. Neste caso, o vigor de uma planta no início do seu ciclo influencia diretamente a produção de grãos, por apresentar condições potenciais de definir maior número de primórdios na inflorescência durante a sua iniciação, como sugerido por Ledent (1982). Deste modo, todos os parâmetros que caracterizaram as plantas mais competitivas, durante o período de afilhamento, podem se tornar parâmetros de estimativa de plantas potencialmente mais produtivas, considerando as variações dentro da mesma monocultura.

Dentre os parâmetros inicialmente avaliados, o comprimento da bainha, assim como observado no afilhamento, apresentou fraca associação com a massa seca, estatura, número de espiguetas e afilhos, no florescimento, principalmente em aveia (tabela 5). Entretanto, o estádio de desenvolvimento foliar, que segundo Krenzer et al. (1991) pode expressar a qualidade de germinação e a qualidade entre microambientes de um cultivo, foi diretamente relacionado com a habilidade competitiva de cada planta (massa seca e diâmetro do pseudocolmo), no início do desenvolvimento (figura 1, tabela 2). Este parâmetro inicial também pode garantir uma grande estimativa do potencial de produção e crescimento da planta no florescimento, quando comparado entre plantas da mesma população (tabelas 5, 6). No geral, as plantas de

Tabela 5. Coeficientes de correlações entre os parâmetros avaliados no afilhamento e no florescimento, em 120 plantas de aveia (UFRGS 15) cultivadas em canteiros (experimento III). FA/UFRGS, Porto Alegre, RS. 1997.

\begin{tabular}{|c|c|c|c|c|c|c|c|c|}
\hline \multirow[b]{3}{*}{ Florescimento } & \multicolumn{8}{|c|}{ Afilhamento } \\
\hline & \multirow{2}{*}{$\begin{array}{l}\text { Comp. } \\
\text { bainha }^{1}\end{array}$} & \multirow{2}{*}{$\begin{array}{l}\text { Diâmetro } \\
\text { pseud. }\end{array}$} & \multicolumn{5}{|c|}{ Desenvolvimento foliar ${ }^{3}$} & \multirow{2}{*}{$\begin{array}{c}\text { Ordem de } \\
\text { emergência }\end{array}$} \\
\hline & & & $\mathrm{CP}$ & A1 & $\mathrm{A} 2$ & A0 & Soma & \\
\hline Estatura & ns ${ }^{5}$ & 0,30 & 0,40 & 0,39 & 0,33 & $\mathrm{~ns}$ & 0,41 & $-0,48$ \\
\hline Massa seca & 0,24 & 0,48 & 0,62 & 0,60 & 0,56 & $\mathrm{~ns}$ & 0,68 & $-0,58$ \\
\hline Comprimento da panícula & 0,27 & 0,24 & 0,43 & 0,42 & 0,36 & $\mathrm{~ns}$ & 0,43 & $-0,57$ \\
\hline Total de espiguetas & 0,24 & 0,41 & 0,58 & 0,57 & 0,52 & $\mathrm{~ns}$ & 0,62 & $-0,61$ \\
\hline N. espiguetas férteis & $\mathrm{ns}$ & 0,42 & 0,54 & 0,53 & 0,47 & $\mathrm{~ns}$ & 0,58 & $-0,54$ \\
\hline N. espiguetas estéreis & $\mathrm{ns}$ & $\mathrm{ns}$ & $\mathrm{ns}$ & $\mathrm{ns}$ & ns & ns & $\mathrm{ns}$ & $\mathrm{ns}$ \\
\hline Total de afilhos & $\mathrm{ns}$ & $\mathrm{ns}$ & $\mathrm{ns}$ & $\mathrm{ns}$ & ns & $\mathrm{ns}$ & $\mathrm{ns}$ & $\mathrm{ns}$ \\
\hline N. afilhos férteis & $\mathrm{ns}$ & $\mathrm{ns}$ & $\mathrm{ns}$ & $\mathrm{ns}$ & ns & ns & $\mathrm{ns}$ & $\mathrm{ns}$ \\
\hline N. afilhos estéreis & $\mathrm{ns}$ & $\mathrm{ns}$ & $\mathrm{ns}$ & $\mathrm{ns}$ & ns & $\mathrm{ns}$ & $\mathrm{ns}$ & $\mathrm{ns}$ \\
\hline \multicolumn{9}{|c|}{1 Comprimento da bainha da última folha expandida. } \\
\hline \multicolumn{9}{|c|}{2 Diâmetro do pseudocolmo. } \\
\hline \multirow{2}{*}{\multicolumn{9}{|c|}{$\begin{array}{l}3 \text { Desenvolvimento foliar medido pela escala Haun do colmo principal (CP), dos afilhos da primeira folha (A1), da segunda folha } \\
\text { (A2), do nó do coleóptilo (A0) e o somatório foliar da planta (Soma). } \\
4 \text { Ordem de emergência das plantas na comunidade. }\end{array}$}} \\
\hline & & & & & & & & \\
\hline \multicolumn{9}{|l|}{5 Coeficientes de correlaç } \\
\hline
\end{tabular}


Tabela 6. Coeficientes de correlação entre os parâmetros avaliados no afilhamento e no florescimento, em 120 plantas de trigo (EMBRAPA 16) cultivadas em canteiros (experimento III). FA/UFRGS, Porto Alegre, RS. 1997.

\begin{tabular}{|c|c|c|c|c|c|c|c|c|c|}
\hline \multirow[b]{3}{*}{ Florescimento } & \multicolumn{9}{|c|}{ Afilhamento } \\
\hline & \multirow{2}{*}{$\begin{array}{l}\text { Comp. } \\
\text { bainha }\end{array}$} & \multirow{2}{*}{$\begin{array}{l}\text { Diâmetro } \\
\text { pseud. }^{2}\end{array}$} & \multirow[b]{2}{*}{$\mathrm{CP}$} & \multicolumn{4}{|c|}{ Desenvolvimento foliar ${ }^{3}$} & \multirow[b]{2}{*}{ Soma } & \multirow{2}{*}{$\begin{array}{l}\text { Ordem de } \\
\text { emergência }{ }^{4}\end{array}$} \\
\hline & & & & A1 & A2 & $\mathrm{A} 3$ & A0 & & \\
\hline Estatura & $0,38^{5}$ & 0,48 & 0,66 & $\mathrm{~ns}$ & 0,64 & 0,69 & 0,27 & 0,65 & $-0,53$ \\
\hline Massa seca & 0,35 & 0,55 & 0,54 & $\mathrm{~ns}$ & 0,67 & 0,60 & 0,31 & 0,67 & $-0,41$ \\
\hline Comprimento da panícula & 0,32 & 0,48 & 0,54 & $\mathrm{~ns}$ & 0,59 & 0,63 & $\mathrm{~ns}$ & 0,63 & $-0,41$ \\
\hline Total de espiguetas & 0,32 & 0,47 & 0,50 & $\mathrm{~ns}$ & 0,54 & 0,60 & $\mathrm{~ns}$ & 0,56 & $-0,35$ \\
\hline N. espiguetas férteis & 0,33 & 0,48 & 0,53 & $\mathrm{~ns}$ & 0,59 & 0,62 & 0,28 & 0,65 & $-0,42$ \\
\hline N. espiguetas estéreis & $\mathrm{ns}$ & ns & $\mathrm{ns}$ & $\mathrm{ns}$ & $\mathrm{ns}$ & $\mathrm{ns}$ & $\mathrm{ns}$ & $\mathrm{ns}$ & ns \\
\hline Total de afilhos & 0,28 & 0,31 & 0,30 & $\mathrm{~ns}$ & 0,36 & 0,46 & $\mathrm{~ns}$ & 0,43 & $-0,33$ \\
\hline N. afilhos férteis & $\mathrm{ns}$ & 0,24 & $\mathrm{~ns}$ & $\mathrm{~ns}$ & 0,26 & $\mathrm{~ns}$ & $\mathrm{~ns}$ & 0,29 & $\mathrm{~ns}$ \\
\hline N. afilhos estéreis & $\mathrm{ns}$ & $\mathrm{ns}$ & $\mathrm{ns}$ & $\mathrm{ns}$ & $\mathrm{ns}$ & 0,36 & $\mathrm{~ns}$ & 0,28 & $-0,27$ \\
\hline \multicolumn{10}{|c|}{1 Comprimento da bainha da última folha expandida. } \\
\hline \multicolumn{10}{|l|}{2 Diâmetro do pseudocolmo. } \\
\hline \multicolumn{10}{|c|}{$\begin{array}{l}3 \text { Desenvolvimento foliar medido pela escala Haun do colmo principal (CP), dos afilhos da axila da primeira folha (A1), da } \\
\text { segunda folha (A2), do nó do coleóptilo (A0) e o somatório foliar da planta (Soma). }\end{array}$} \\
\hline \multicolumn{10}{|c|}{4 Ordem de emergência das plantas na comunidade. } \\
\hline \multicolumn{10}{|c|}{5 Coeficientes de correlação significativos aos níveis de $1 \%(r>0,23$} \\
\hline
\end{tabular}

trigo e aveia que apresentaram maior desenvolvimento foliar no colmo principal, no afilhamento, resultaram em plantas de maior porte (massa seca e estatura) e potencial de produção (total de espiguetas e espiguetas férteis) no florescimento.

As plantas com alta habilidade competitiva também apresentaram afilhos mais desenvolvidos, principalmente o primeiro e segundo afilho (tabela 1). O estádio foliar destes afilhos também caracterizou as plantas que, no florescimento, tiveram maior potencial de produção (tabelas 5,6). Esta associação com a produção de grãos, neste caso, é de forma indireta pois os afilhos caracterizaram as plantas vigorosas que suportaram tanto o desenvolvimento destes como também a iniciação dos primórdios de espiguetas, no colmo principal. Em condições menos favoráveis, como mostrado por Galli (1996) ou com variedades que não apresentam alto grau de afilhamento (Wobeto 1994), o desenvolvimento dos afilhos tende a não se relacionar com as características finais de produção, principalmente pela dominância que o colmo principal exerce sobre o desenvolvimento dos afilhos.

De todos os parâmetros avaliados durante o início do estabelecimento da população, a data de emergência destacou-se como o principal fator de variabilidade de crescimento e desenvolvimento, avaliados tanto no afilhamento como no florescimento (figura 1, tabelas 5,6). Desta forma, a data de emergência apresenta influência direta sobre a performance que uma planta pode apresentar na população, estando inversamente associada aos componentes de produção (tabelas 5,6). Isto está de acordo com os resultados da literatura, os quais citam a variação na data da emergência como um fator que pode influenciar diretamente o potencial de produção de uma planta (Knight 1983, Peterson et al. 1989).

Com base nestes resultados pode-se caracterizar que as plantas que emergem tardiamente dentro da população, da mesma espécie, apresentam menor massa seca, principalmente pelo menor crescimento e desenvolvimento foliar do colmo principal, o que determina menor diâmetro do pseudocolmo. Estas plantas também apresentam menor desenvolvimento de afilhos e primórdios de espiguetas, reduzindo como um todo a capacidade de incremento no rendimento por planta. Este comportamento de plantas em população pode ser explicado por variações em profundidade de semeaduras, tamanho de sementes, velocidade de germinação, disponibilidade hídrica, entre outros, que promovem emergências tardias resultando na influência direta sobre a sobrevivência ou as características finais que uma planta pode apresentar (Lafond \& Baker 1986, Benjamin 1990, Krenzer et al. 1991, Gan \& Stobbe 1996). Sendo assim, todos os esforços na obtenção de emergências uniformes podem estar contribuindo para condições equivalentes de competição entre plantas, 
podendo resultar em menores amplitudes na variação de produção por planta no final do ciclo, o que consequentemente irá potencializar a produção por área.

Agradecimentos - Os autores agradecem a Dra. M.R. Braga e a MSc. L. I. M. Amaral pelas revisões e sugestões no texto, e ao CNPq pelo financiamento parcial deste trabalho.

\section{Referências bibliográficas}

BAUER, A., FRANK, A.B. \& BLACK, A.L. 1984. Estimation of spring wheat leaf growth and anthesis from air temperature. Agronomy Journal 76:829-8354.

BENJAMIN, L.R. 1990. Variation in time of seedling emergence within populations: a feature that determines individual growth and development. Advances in Agronomy 41:1-25.

BENJAMIN, L.R. \& HARDWICK, R.C. 1986. Sources of variation and measures of variability in even-aged stands of plants. Annals of Botany 58:757-778.

BONAN, G.B. 1991. Density effects on the size structure of annual plant populations: an indication of neighbourhood competition. Annals of Botany 68:341-347.

BONNETT, O.T. 1966. Inflorescences of maize, wheat, rye, barley, and oats: their initiation and development. (Bulletin 721). University of Illinois, College of Agriculture, Agricultural Experiment Station.

CHAFAI-ELALAOUI, A. \& SIMMONS, S.R. 1988. Quantitative translocation of photoassimilates from nonsurviving tillers in barley. Crop Science 28:969-972.

FRANK, A.B. \& BAUER, A. 1996. Temperature, nitrogen, and carbon dioxide effects on spring wheat development and spikelet numbers. Crop Science 36:659-665.

GALLI, A.P. 1996. Competição intraespecífica e o crescimento de trigo e aveia em duas épocas de cultivo. Dissertação de mestrado, Universidade Federal do Rio Grande do Sul, Porto Alegre.

GAN, Y. \& STOBBE, E.H. 1996. Mainstem leaf stage and its relation to single plant grain yield in spring wheat. Crop Science 36:628-632.

GOMES, F.P. 1987. Curso de estatística experimental. 12 ed. Escola Superior de Agricultura "Luiz de Queiroz", Piracicaba.

HAUN, J.R. 1973. Visual quantification of wheat development. Agronomy Journal 65:116-119.
KIRBY, E.J.M. 1995. Factors affecting rate of leaf emergence in barley and wheat. Crop Science 35:11-19.

KNIGHT, R. 1983. Some factors causing variation in the yield of individual plants of wheat. Australian Journal of Agricultural Research 34:219-228.

KRENZER JR, E.G, NIPP, T.L., \& MCNEW, R.W. 1991. Winter wheat mainstem leaf appearance and tiller formation vs. moisture treatment. Agronomy Journal 83:663-667.

LAFOND, G.P. \& BAKER, R.J. 1986. Effects of genotype and seed size on speed of emergence and seedling vigor in nine spring wheat cultivars. Crop Science 26:341-346.

LAITANO, C.S. 1997. Desenvolvimento do meristema apical de aveia e trigo e sua relação com as características morfológicas. Dissertação de mestrado, Universidade Federal do Rio Grande do Sul, Porto Alegre.

LEDENT, J.F. 1982. Morphology and yield in winter wheat grown in high yielding conditions. Crop Science 22:1115-1120.

LIANG, Y.L. \& RICHARDS, R.A. 1994. Coleoptile tiller development is associated with fast early vigour in wheat. Euphytica 80:119-124.

LOZANO, C.M., DIOS, M.A., BODEGA, J.L. \& GARRIDO, G.G. 1984. Relaciones entre los estados de desarrollo apical y caracteristicas morfologicas en plantas de trigo. Revista da Facultad de Agronomia 5:51-63.

MIRALLES, D.J., FERRO, B.C. \& SLAFER, G.A. 2001. Developmental responses to sowing date in wheat, barley and rapeseed. Field Crops Research 71: 211-223.

OOSTERHUIS, D.M. \& CARTWRIGHT, P.M. 1983. Spike differentiation and floret survival in semidwarf spring wheat as affected by water stress and photoperiod. Crop Science 23:711-717.

PETERMAN, C.J., SEARS, R.G. \& KANEMASU, E.T. 1985. Rate and duration of spikelet initiation in 10 winter wheat cultivars. Crop Science 25:221-225.

PETERSON, C.M., KLEPPER, B. \& RICKMAN, R.W. 1989. Seed reserves and seedling development in winter wheat. Agronomy Journal 81:245-251.

SHANAHAN, J.F., DONNELLY, K.J., SMITH, D.H. \& SMIKA, D.E. 1985. Shoot developmental properties associated with grain yield in winter wheat. Crop Science 65:770-775.

WOBETO, C. 1994. Padrão de afilhamento, sobrevivência de afilhos e suas relações com o rendimento de grãos em trigo. Dissertação de mestrado, Universidade Federal do Rio Grande do Sul, Porto Alegre. 